\title{
A Rare Case of Radiation Induced Hypoparathyroidism Resulting in Hypocalcaemic Seizures and Brain Calcinosis
}

\author{
Mangalasundaram Rangaswami ${ }^{1}$, Moorthi Anitha², Mohanachandran Sreelakshmi ${ }^{3}$ \\ ${ }^{1}$ Department of General Medicine, Government Vellore Medical College, Adukkamparai, Tamilnadu, India. \\ ${ }^{2}$ Department of General Medicine, Government Vellore Medical College, Adukkamparai, Tamilnadu, India. \\ ${ }^{3}$ Department of General Medicine, Government Vellore Medical College, Adukkamparai, Tamilnadu, India.
}

\section{PRESENTATION OF CASE}

A 53-year-old female with 2 episodes of seizures was brought to the hospital. Seizure episode was manifested as tonic contraction of all limbs, lip smacking movements and frothing from mouth and loss of consciousness for few minutes, after which she had recovered completely. No history of head injury, or limb weakness, or deviation of angle of mouth to any side, headache or fever.

History of thyroid surgery about 20 years back along with radio-iodine therapy following surgery, as informed by the patient and attender. But details regarding thyroidectomy procedure, radio-iodine therapy were not available.

Not a known patient of diabetes, hypertension, epilepsy, or heart disease. She is on Thyroxine $100 \mathrm{mcg}$,

General and systemic examination was normal, except for positive Trousseau sign, dysdiadochokinesia \& positive finger nose test.

Out of many hereditary and acquired causes of hypoparathyroidism, radiation induced damage secondary to radioiodine therapy for hyperthyroidism has been implicated as a rare cause. This patient took radiation therapy which resulted in hypoparathyroidism, which lead to hypocalcaemia and resulting seizures, along with bilaterally symmetrical basal ganglia calcification. To add to the interest, this patient also had bilateral cerebellar calcification.

\section{DIFFERENTIAL DIAGNOSES}

1. Acute Cerebrovascular Accident.

2. CNS metastasis, from doubtful carcinoma thyroid.

3. Metabolic seizures.
Corresponding Author: Dr. Anitha Moorthi, \#622, New Street, Vellur Village \& Post, Santhavasal Polur Taluk, Thiruvannamalai-606905 District, Tamilnadu, India.

E-mail:dranithamoorthi@gmail.com

DOI: $10.14260 / j e m d s / 2020 / 354$

Financial or Other Competing Interests: None.

How to Cite This Article:

Rangaswami M, Anitha M, Sreelakshmi M. $A$ rare case of radiation induced hypoparathyroidism resulting in hypocalcaemic seizures and brain calcinosis. J. Evolution Med. Dent. Sci. 2020;9(20):1619-1621, DOI: $10.14260 /$ jemds $/ 2020 / 354$

Submission 30-12-2019, Peer Review 28-04-2020, Acceptance 04-05-2020, Published 18-05-2020.

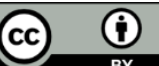




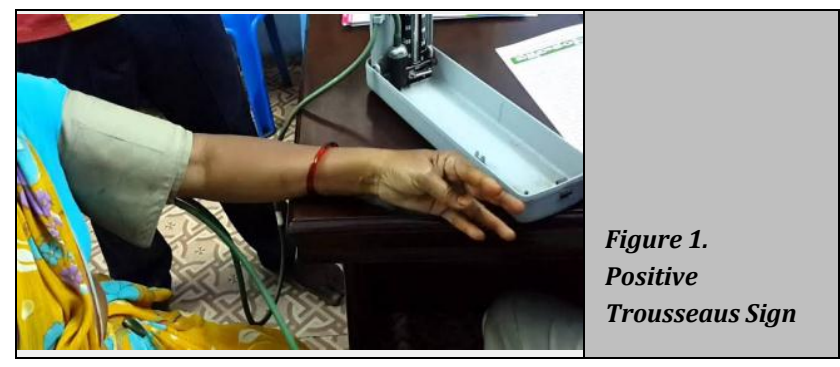

Electrocardiogram revealed normal sinus rhythm with prolonged QT interval (548msec). CT Brain showed Non homogenous hyperdensity in bilateral basal ganglia (Putamen caudate nucleus and globus pallidus) and cerebellar hemispheres \& mildly dilated ventricles.
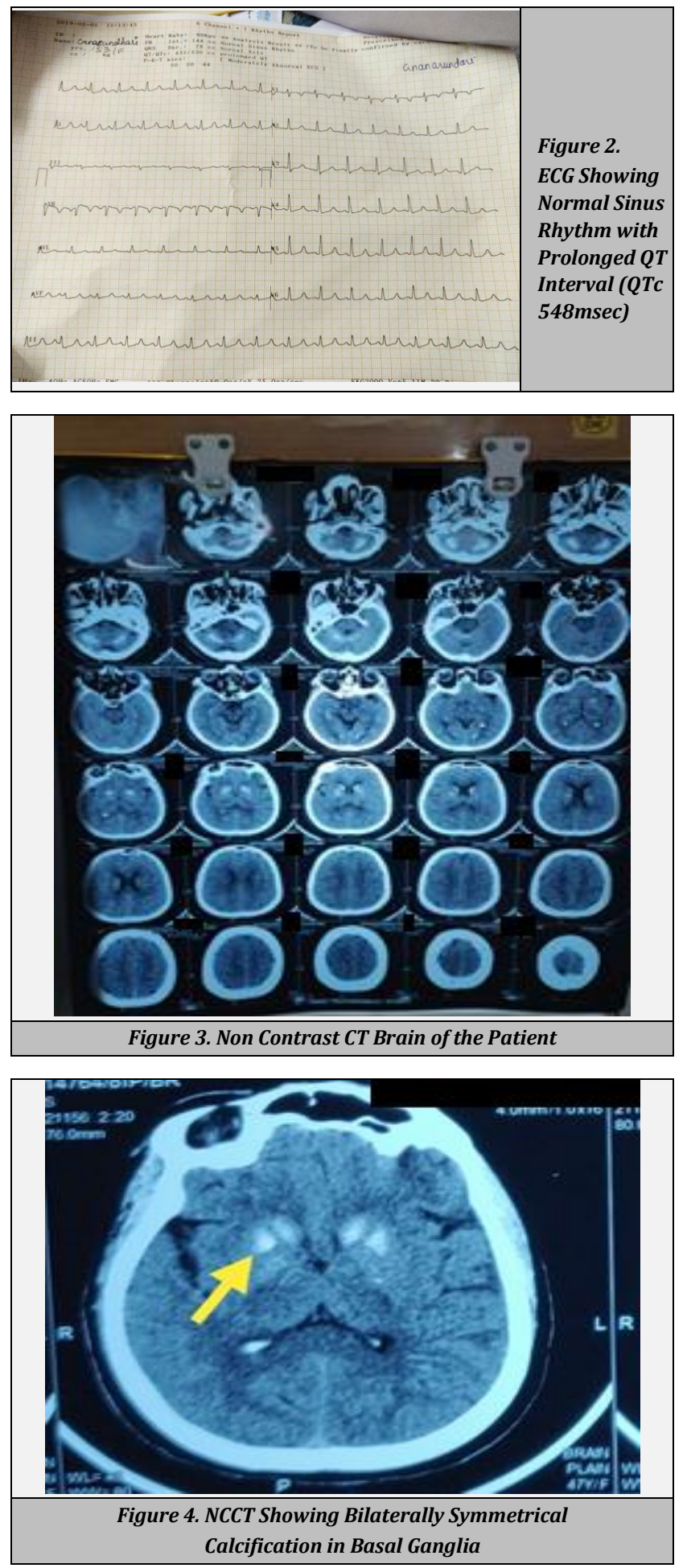

USG Neck revealed surgically absent left lobe and isthmus with right lobe normal in size and uniform echotexture without any focal lesions. FNAC from right lobe revealed features suggestive of colloid nodule.

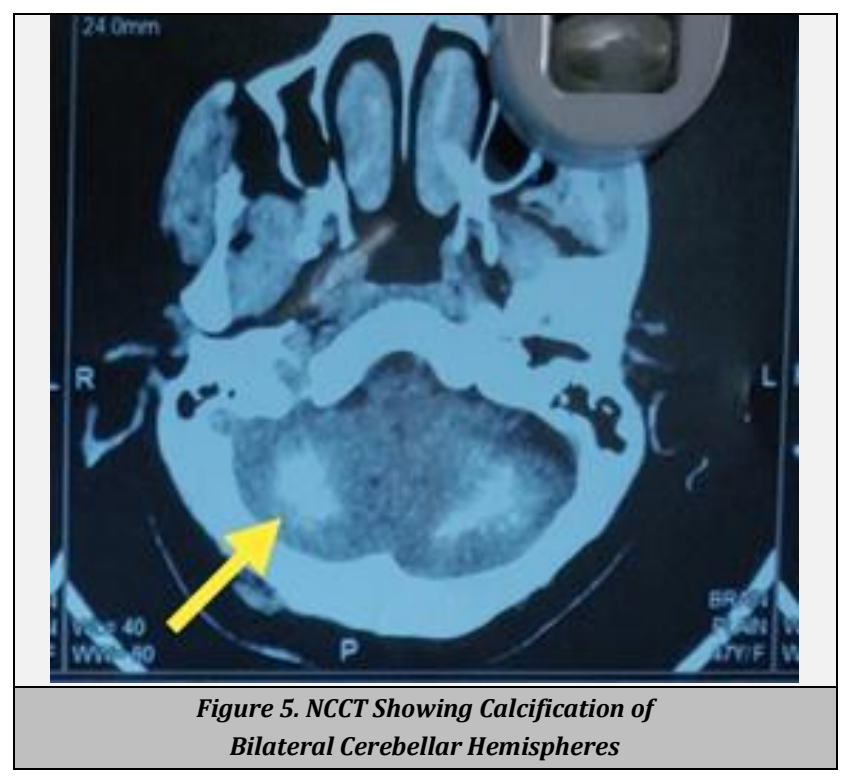

ENT opinion obtained, video laryngoscopy done, \& revealed Left vocal cord palsy. CT Neck was within normal limits.

\begin{tabular}{|c|c|c|}
\hline Investigations & Values & Ref. \\
\hline Corrected Calcium & $6.7 \mathrm{mg} / \mathrm{dl}$ & $8.5-10.5 \mathrm{mg} / \mathrm{dl}$ \\
\hline S. Magnesium & $2.1 \mathrm{mg} / \mathrm{dl}$ & $1.7-2.2 \mathrm{mg} / \mathrm{dl}$ \\
\hline Urine Calcium: Urine. Creatinine & 0.30 & $<0.14$ \\
\hline TSH & 20.89 & $0.35-5.50$ \\
\hline S. Parathyroid hormone & $<.23 \mathrm{pg} / \mathrm{ml}$ & $18.50-88.0 \mathrm{pg} / \mathrm{ml}$ \\
\hline Vit D & $19.66 \mathrm{ng} / \mathrm{ml}$ & $30-100 \mathrm{ng} / \mathrm{ml}$ \\
\hline S. Phosphorous & $6.1 \mathrm{mg} / \mathrm{dl}$ & $2.5-5.0 \mathrm{mg} / \mathrm{dl}$ \\
\hline S. Calcitonin & $<2 \mathrm{pg} / \mathrm{ml}$ & $<5.0 \mathrm{pg} / \mathrm{ml}$ \\
\hline \multicolumn{2}{|c|}{ Table 1. Investigation Results with Reference Values } \\
\hline
\end{tabular}

\section{PATHOLOGICAL DISCUSSION}

Hemogram, liver and renal function were within normal limits. Abnormalities found were, reduced serum calcium level, insufficient vitamin D levels, increased urine calcium excretion, TFT revealed hypothyroid status, reduced serum parathyroid hormone level.

Hypoparathyroidism can be hereditary or acquired. It usually presents with hypocalcaemia. Idiopathic \& Syndromic causes include DiGeorge syndrome, Kenney Caffey syndrome Polyglandular autoimmune type 1 deficiency. Acquired or secondary causes for chronic hypoparathyroidism include inadvertent surgical removal of all parathyroid glands. In some instances, not all tissue is removed, but the remaining tissue undergoes vascular supply compromise secondary to fibrotic change in neck after surgery. Rare causes include Radiation induced damage subsequent to radioiodine therapy of hyperthyroidism, Glandular damage in hemochromatosis/hemosiderosis after repeated transfusions and Infections ${ }^{1}$. Anterior neck surgery is the most common cause of acquired hypoparathyroidism, and is responsible for $75 \%$ of the cases ${ }^{2}$. The next most common cause in adults is thought to be autoimmune diseases either affecting parathyroids alone or along with other endocrine glands. Exact prevalence of radiation induced chronic 
hypoparathyroidism has not been established, probably due to its rarity 2 .

Clinical symptoms correlate with acuteness of hypocalcaemia and absolute level of serum calcium ${ }^{3}$. Patients with acute drop in S. calcium have more dramatic symptoms than those with chronic hypocalcaemia. Neurological manifestations include myoclonic jerks, twitching, new onset seizures, or worsening of seizures due to cerebral hypocalcemia. Many have cognitive dysfunction, easy fatigability, and higher incidence of anxiety, depression, overall reduced quality of life occurs in hypoparathyroid groups. Basal ganglia and intracerebral calcifications maybe associated with extrapyramidal movements and psychosis. Cardiac manifestations are prolonged QT interval, T-wave alternans, acute cardiomyopathy, and congestive cardiac failure due to decreased cardiac contractility, due to low serum calcium and low PTH, as there are PTH receptors in cardiac myocytes ${ }^{3}$. Recent studies have shown increased risk of posterior subcapsular cataract due to elevated Ca-P product in the lens. Physical examination of a patient with hypocalcaemia include assessment of neuromuscular hyperexcitability by testing Chvostek's and Trousseau's signs. Chvostek's sign is positive in $15 \%$ of individuals with normal serum calcium ${ }^{3}$.

\section{DISCUSSION MANAGEMENT}

Treatment modality aims at improving serum calcium level by aiding its absorption, with very high levels of calcium and vitamin D supplementation. But these may not reverse the lowered urinary calcium reabsorption, typical of hypoparathyroidism, which can result in nephrocalcinosis and increase the risk of $\mathrm{CKD}^{4}$. Impaired renal function is the most common complication seen in patients treated for hypoparathyroidism. One study found rates of CKD stage 3 or higher were 2-17 fold higher in hypoparathyroid patients than normal cohort. Thiazide diuretic will lower the urine calcium by as much as $100 \mathrm{mg} /$ day in hypoparathyroid patients on vitamin $\mathrm{D}$, provided they are maintained on low sodium diet ${ }^{4}$. Subsequently full length PTH molecule has been shown to be effective, and is now FDA approved for therapy of hypoparathyroidism ${ }^{4}$.

Causes of bilaterally symmetrical basal ganglia calcification are Physiological, Hypoparathyroidism, Hyperparathyroidism Fahr's syndrome (Familial idiopathic cerebral calcification), Carbon monoxide intoxication Lead poisoning, Tuberous sclerosis, Cockayne's syndrome, Post infectious, Acquired immunodeficiency syndrome (Especially in children), Radiation therapy, Methotrexate therapy, Kearnes-Sayre syndrome and other mitochondrial diseases, Familial encephalopathies and Down syndrome ${ }^{5}$. In spite of having bilaterally symmetrical basal ganglia calcification, this patient also had bilateral cerebellar calcification, which has been documented very rarely in hypoparathyroidism, but in Fahr's syndrome.

\section{FINAL DIAGNOSIS}

Hypothyroidism, with iatrogenic (probably radiation induced) hypoparathyroidism resulting in hypocalcaemia and brain calcinosis, leading to seizures.

\section{CONCLUSIONS}

Radiation induced hypoparathyroidism has been implicated as a rare cause of hypoparathyroidism and very few cases have been reported so far with this aetiology. This patient developed subsequent brain calcification due to calcium phosphate complex deposition, which included bilateral cerebellar hemispheres also; whereas, hypoparathyroidism usually results in bilateral basal ganglial calcification.

\section{REFERENCES}

[1] Bringhurst RF, Demay MB, Henry M. Hormones and disorders of mineral metabolism. In: Melmed $\mathrm{S}$, Polonosky KS, eds. Williams Textbook of Endocrinology. $13^{\text {th }}$ edn. Philadelphia: Elsevier 2011: p. 1254-307.

[2] Clarke BL, Brown EM, Collins MT, et al. Epidemiology and diagnosis of hypoparathyroidism. The Journal of Clinical Endocrinology \& Metabolism 2016;101 (6):2284-99.

[3] Abate EG, Clarke BL. Review of hypoparathyroidism. Frontiers in Endocrinology (Lausanne) 2017;7:172.

[4] Potts JT, Juppner HW. Disorders of the parathyroid gland and calcium homeostasis. In: Jameson JL, Fauci AS, Kasper DL, eds. Harrison's Principles of Internal Medicine. 20 th edn. New York: McGraw-Hill Publication 2018: p. 292141.

[5] Rizvi I, Ansari NA, Beg M, et al. Widespread intracranial calcification, seizures and extrapyramidal manifestations in a case of hypoparathyroidism. North American Journal of Medical Sciences 2012;4 (8):369-72. 